\title{
APONTAMENTOS INICIAIS ACERCA DE UMA CARTA ESCRITA POR AL-BIRUNI (973-1048) NO SÉCULO XI
}

\section{INITIAL NOTES ON THE LETTER WRITTEN BY AL-BIRUNI (973-1048) IN CENTURY XI}

\author{
Francisco Neto Lima de Souza ${ }^{1}$; Giselle Costa de Sousa ${ }^{2}$
}

\begin{abstract}
RESUMO
O trabalho ora apresentado se concentra na área de História da Matemática, mais precisamente na História da Matemática do Islã medieval. Discutiremos informações levantadas sobre uma carta escrita por al-Biruni que diz respeito a Lei dos Senos na Trigonometria Triangular Esférica, trataremos de seu conteúdo e estrutura, bem como observaremos a forma de registro do conhecimento na tentativa de responder à pergunta que norteia a construção do presente artigo: o que pode se falar sobre a estrutura da carta escrita por al-Biruni e que aspectos observados na carta, podem nortear a construção de uma narrativa que se aproxime de uma perspectiva atualizada de registrar a História? Usaremos para o desenvolvimento do trabalho historiográfico uma tradução da carta que está em inglês e foi encontrada no livro Beyruni'ye Armagan, mais precisamente no capítulo intitulado Al Beyruni's Letter on Abu Nasr Mansur's Demonstration of the Sine Law que ocupa as páginas 183 a 197 e tem autoria do Dr. Aydin Sayli. No que diz respeito a carta, a original está em árabe e o livro supracitado consta, ainda, uma tradução turca. A partir do estudo da versão inglesa, em confronto com demais versões presentes no livro, verificamos que ela trata de seis casos da lei dos senos, diluídos em quatro demonstrações, os três primeiros casos são associados a Trigonometria Triangular Esférica (TTE) enquanto os últimos três, são associados a Geometria Plana. Assim, nosso objetivo é apresentar parte de uma análise historiográfica (ainda em desenvolvimento) e, pretendemos alcançá-lo pelo desenvolvimento desse trabalho que, mediante a questões metodológicas, se associa a uma pesquisa com abordagem qualitativa e de procedimentos documentais e bibliográficos. Como resultado, apresentamos uma apreciação preliminar da carta e possíveis apontamentos que podem nortear a construção de uma narrativa mais contextualizada sobre o documento.
\end{abstract}

Palavras-chave: al-Biruni; carta sobre a lei dos senos; Trigonometria Triangular Esférica.

\footnotetext{
ABSTRACT

The work presented here focuses on the area of the History of Mathematics, more precisely on the History of Mathematics of medieval Islam. We will discuss information raised about a letter written by al-Biruni regarding the Law of Senos in Spherical Triangular Trigonometry, we will

${ }^{1}$ Mestrado em andamento. Universidade Federal do Rio Grande do Norte (UFRN). Professor efetivo do quadro da Secretaria de Educação, Ciência e Tecnologia da Paraíba (SECT-PB), Cabedelo, PB, Brasil. Endereço para correspondência: Rua Claudionor Figueredo, 404 - Nova Descoberta, Natal, RN, Brasil, CEP: 59075-260. E-mail: 20121053060294@ufrn.edu.br

iD ORCID iD: https://orcid.org/0000-0001-5340-8630.

2 Doutora. Universidade Federal do Rio Grande do Norte (UFRN). Professora associada do DMAT (UFRN), Natal, RN, Brasil. Endereço para correspondência: Cirilo Moreira, 261 - Nazaré, Natal, RN, Brasil, CEP: 59062-130.E-mail: gisellematufrn@mail.com.

(iD) ORCID iD: https://orcid.org/0000-0003-0213-4179.
} 
deal with its content and structure, as well as observe the form of knowledge registration in an attempt to answer the question that guides the construction of this article: what can be said about the structure of the letter written by al-Biruni and what aspects observed in the letter can guide the construction of a narrative that comes close to an updated perspective of recording History? We will use a translation of the letter in English for the development of the historiographic work, found in the book Beyruni'ye Armagan, more precisely in the chapter entitled Al Beyruni's Letter on Abu Nasr Mansur's Demonstration of the Sine Law that occupies pages 183 to 197 by Dr. Aydin Sayli. With regard to the letter, the original is in Arabic and the aforementioned book also has a Turkish translation. From the study of the English version in comparison with other versions, we found that it deals with six cases of the law of sines are identified, diluted in four demonstrations, the first three cases are associated with Spherical Triangular Trigonometry (TTE) while the last three are associated with Flat Geometry. Thus, our goal is to present part of a historiographic analysis (still under development) and, we intend to achieve it by developing a work that, through methodological issues, is associated with research with a qualitative approach and documentary and bibliographic procedures. As a result, we present a preliminary assessment of the letterand possible notes that can guide the construction of a more contextualized narrative about the document.

Keywords: al-Biruni; letter on the law of sines; Spherical Triangular Trigonometry. 


\section{Início de conversa}

O presente trabalho é um recorte de uma pesquisa do Mestrado Profissional em Ensino de Ciências Naturais e Matemática, em andamento, vinculado ao Programa de Pós Graduação em Ensino de Ciências Naturais e Matemática da Universidade Federal do Rio Grande do Norte.

No trabalho de mestrado, estudamos a História da Matemática, especificamente a História da Matemática do Islã Medieval do século XI cujo contexto é observado a partir da figura do Abu Raihan Muhammad ibn Ahmad al-Biruni ou, simplesmente, al-Biruni. Essa personalidade nasce em 15 de setembro de 973 em uma região bem próxima ao Mar de Aral, que hoje se chama Biruni, enquanto forma de reconhecimento as suas contribuições para áreas de conhecimento diversas.

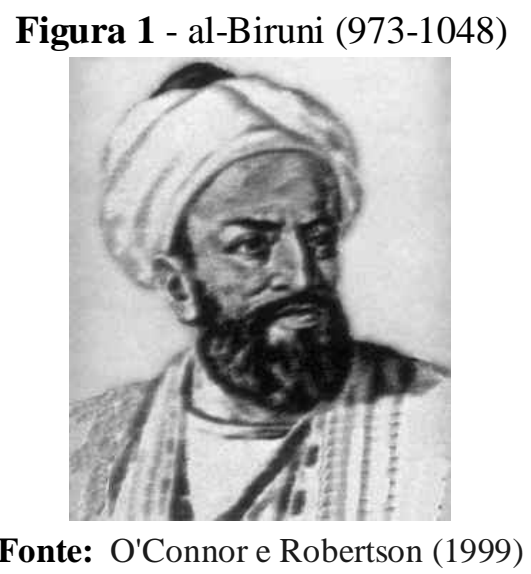

Al-Biruni é apontado nas bibliografias disponíveis como sendo um estudioso com habilidades em áreas do conhecimento diversas (comum em seu período e região), nesse sentido, contempla estudo nas áreas de Farmacologia, Medicina, Geografia, astronomia e Matemática. Em especial, quando observamos a Matemática desenvolvida por al-Biruni podemos observar uma ferramenta que possibilita o estudo de sua principal área de interesse, a Astronomia. De fato, para começar a entender a Astronomia, ele teve que se tornar especialista em campos que hoje conhecemos como Aritmética, Álgebra e Geometria, o que o torna um polímata e deu a sua Matemática um lugar de muita importância dentro do seu vasto trabalho. (GAFUROV, 1974; SCHEPPLER, 2006)

Considerando suas produções, em especial as que tem ligação com a Geometria, chegamos ao nosso objeto de pesquisa do mestrado: uma carta que trata da Lei dos Senos na Trigonometria Triangular Esférica que apresenta quatro demonstrações sobre a 
referida lei. É de nosso interesse, tendo em vista o âmbito de desenvolvimento do trabalho, olhar a carta para além de um documento histórico, de modo que pretendemos apreciar esse documento como um provedor de reflexões para o ensino da Matemática.

Assim, buscamos responder com a pesquisa de mestrado, e tendo em vista o objeto de estudo, a seguinte questão foco: como explorar os aspectos hitóricos-matemáticos, presentes no discurso de al-Biruni sobre a Lei dos Senos na Trigonometria Triângular Esférica em um caderno de atividades direcionado a formação de professores de Matemática? Para tanto, estudamos apresentar um produto educacional, na forma de um caderno de atividades, pautado no uso da História da Matemática para o ensino, considerando a interface proposta por Saito e Dias $(2013)^{3}$ e uma conexão dessa com a aliança entre História da Matemática, Tecnologias Digitais e Investigação Matemática com aporte em Sousa $(2020)^{4}$.

Esse propósito está diretamente ligado a existência do trabalho em questão, pois seria muito difícil, ou mesmo inviável, o desenvolvimento de uma interface entre História da Matemática e ensino com as historiografias da Matemática que estão disponíveis na conjuntura tradicional. Saito (2015) retrata isso com bastante propriedade quando comenta que as historiografias tradicionais da História da Matemática não parecem ser adequadas para a contrução de uma interface, pois reduzem-se a biografias, dão ênfase ao caráter euristico da Matemática, apresentam um conhecimento acabado e acabam por não valorizar o processo de contrução de conhecimento e nem o contexto que tais processos acontecem.

Desse modo, o autor nos direciona a adotar uma narrativa que possibilite a visão da rede de significados com que se estabeleceram os conceitos e que valorize o processo histórico de constituição do conhecimento matemático. Com isso, visto nossos pressupostos teóricos, buscamos, com o presente artigo, responder a seguinte questão: o que pode se falar sobre a estrutura da carta escrita por al-Biruni e que aspectos

\footnotetext{
${ }^{3}$ A interface entre a HM e ensino pode ser vista enquanto uma "[...] constituição de um conjunto de ações e produções que promova a reflexão sobre o processo histórico da construção do conhecimento matemático para elaborar atividades didáticas que busquem articular história e ensino de matemática" (SAITO; DIAS, 2013, p. 92).

4"Proposta pedagógica para matemática que se consolida pela investigação de problemas/episódios/temas históricos com apoio das tecnológicas que em prol do ensino e aprendizagem da matemática podem ocorrer via o que chamamos de atividades-históricas-com-tecnologias ou investigação-histórica-com-tecnologia." (SOUSA 2020, p.128)
} 
observados nesse documento, podem nortear a construção de uma narrativa que se aproxime de uma perspectiva atualizada de registro da História? Assim, pretendemos neste trabalho, apresentar uma apreciação preliminar do documento à luz dos aspectos almejado para a pesquisa de mestrado.

Logo, consideramos a historiografia atualizada ${ }^{5}$ envolvidos pela motivação de que, tal narrativa, valoriza os contextos de disseminação e criação dos conhecimentos e, por consequência, reconhece a natureza social do conhecimento à medida que compreende a importância das influências que estão envolta desse conhecimento de tal forma que elas não só o influenciam, mas o determinam.

A construção de uma narrativa historicamente orientada em que o contexto e as motivações que envolvem a carta escrita por al-Biruni a Abû Sa'id sejam valorizados é uma condição necessária e imprescindível para que a aliança proposta por Sousa (2020) tenha uma aproximação e se apresente por meio da interface entre História da Matemática e ensino de Saito e Dias (2013). Assim, parte de nossas motivações em realizar a presente análise, emergem desse propósito.

Com isso, resolvemos estruturar o trabalho em quatro partes a contar com a presente introdução que busca, sobretudo, situar a relação do trabalho com um projeto de pesquisa maior e o porquê da emergência do presente artigo. A segunda dessas partes, trata do desenho do referencial metodológico, nesse momento, nos ocupamos em determinar quais categorias metodológicas foram usadas, tendo a preocupação de justificar tais escolhas, haja vista que categorizações se fazem mediante a critérios.

Na sequência, entraremos nas informações levantadas sobre o objeto de estudo analisado/documento, a carta. Assim, a terceira seção traz informações sobre o documento original, bem como, sobre o documento que escolhemos para análise, nos ocupamos também, ainda nessa seção, em propormos levantar informações sobre o conteúdo, a estrutura e organização do documento.

Assim, finalizamos com uma última seção, a quatro, trazendo considerações e apontamentos que foram observados e que podem responder a nossa pergunta, servindo

\footnotetext{
${ }^{5}$ Atualmente, existem duas vertentes historiográficas, uma chamada tradicional, que Saito (2015, p. 26) define como sendo uma narrativa "meramente discursiva que valoriza apenas o resultado e não o processo de construção do conhecimento matemático" e uma outra conhecida por historiografia atualizada, que propõem uma reconstrução histórica que valoriza não só o conteúdo matemático como também faz dos acontecimentos do passado, uma forma de entender o presente, e não o contrário (SAITO, 2015).
} 
de norteadores para construção de uma narrativa historiografia que se aproxime, sempre que possível, da história atualizada. Dito isso, daremos continuidade ao trabalho mostrando adiante a metodologia usada.

\section{Marcos metodológicos da pesquisa}

Conforme Kauark et al (2010) a metodologia é uma parte fundamental do trabalho que consiste prioritariamente na elucidação detalhada e rigorosa de todas as ações desenvolvidas no percurso da pesquisa, bem como a explicação do tipo de pesquisa e dos instrumentos que se utilizaram para a sua efetivação. Nesse sentido, em termos metodológicos, a presente pesquisa propõe uma abordagem qualitativa dos dados e mescla uma pesquisa documental e bibliográfica à medida que se observam os seus procedimentos. Como classificações se fazem mediante a critérios, a seguir, estão postas as justificativas da escolha metodológica.

Godoy (1995, p. 21) enfatiza que "a pesquisa qualitativa ocupa um reconhecido lugar entre as várias possibilidades de se estudar os fenômenos que envolvem os seres humanos e suas intrincadas relações sociais, estabelecidas em diversos ambientes". Dessa forma, a pesquisa qualitativa deixa em segundo plano a importância numérica e se veste de procedimentos que valorizam a compreensão sujeito, o seu contexto e as relações existentes, de modo a fazer uso da subjetividade enquanto principal ferramenta de percepção da realidade estudada.

Assim, estamos preocupados com aspectos que não podem ser quantificados, e por isso, nos valemos dessa abordagem à medida que

\footnotetext{
A adjetivação da pesquisa como qualitativa implica uma ênfase sobre as qualidades das entidades estudadas e sobre os processos e os significados que não podem ser examinados simplesmente em termos de quantidade, volume ou frequência, pois esses processos são construções sociais que abrangem necessariamente uma íntima relação entre o pesquisador e as práticas sociais estudadas. (MARTÍNEZ, 2012, p. 140)
}

Quando propomos um olhar historiográfico sobre o documento, que é o principal objeto de estudo do nosso trabalho (a carta), estamos considerando um contexto marcado pelo enfoque na interpretação do objeto, distanciando nossos objetivos dos aspectos mensuráveis da vida humana. Com isso, caminhamos para uma linha de trabalho que se pauta em uma perspectiva, prioritariamente qualitativa. Essa abordagem, nos conduz a 
uma linha de pensamento interpretativa que estabelece a pesquisa a partir de um marco mais teórico em que construímos o nosso referencial e tecemos, na medida do possível, a análise historiográfica da carta de al-Biruni.

Em um primeiro momento "se utilizando fundamentalmente das contribuições dos diversos autores sobre determinado assunto" (GIL, 2002, p. 45) de modo a obtermos as bases teóricas que compõem o nosso referencial por meio da leitura livros, artigos, dissertações, livros teses, sites e periódicos de nível nacional e internacional com o intuito de delinear a historicidade do tema em questão e construir bases teóricas de sustentação para as ideias trazidas, estamos realizando uma pesquisa bibliográfica.

No entanto, Fontelles et al (2009, p. 7) coloca que é importante apreciarmos a natureza dos documentos usados para elaboração de um trabalho, haja vista que, essa observação é determinante para que a classificação da pesquisa seja feita. Nesse sentido, ele aponta que

\footnotetext{
a pesquisa bibliográfica, a qual utiliza a contribuição fornecida por diversos autores sobre um determinado assunto, enquanto na pesquisa documental, a coleta de informações é realizada em materiais que não receberam qualquer tipo de análise crítica
}

Assim, além da pesquisa bibliográfica, como colocado anteriormente, podemos classificar a pesquisa como documental, pois a construção da narrativa que vai ser vista na próxima seção, leva em consideração a apreciação de uma carta, que até então não foi analisada analiticamente sendo um manuscrito posto num codex que se encontra reescrito, transcrito e traduzido num livro impresso.

Sá-Silva, Almeida e Guindani (2007), afirmam que modalidades de pesquisa que se enquadrem em uma perspectiva documental devem ser valorizadas tendo em vista que são potencialmente ricas quando o quesito é a compreensão de objetos que necessitam de contextualização histórico-cultural, no mais, possibilita a observação de como indivíduos, grupos ou conceitos foram desenvolvidos.

De posse da classificação do nosso trabalho, seguiremos mostrando os primeiros resultados de uma longa busca na tentativa de entender o documento em seu contexto. 


\section{Sobre o documento original}

Como mencionado, o documento em questão é uma carta de al-Biruni que traz a demonstração de seis casos da lei dos senos na trigonometria esférica. $\mathrm{O}$ tratado original se encontra em uma coleção de manuscritos que se intitula Middle Eastern Manuscripts Online 1: Pioneer Orientalists e consiste nos manuscritos árabes de Joseph Justus Scaliger (falecido em 1609), Franciscus Raphelengius (falecido em 1597) e Jacobus Golius (falecido em 1667) que está depositado na Biblioteca da Universidade de Leiden, na Holanda. Essa coleção é constituída por 267 manuscritos raros, alguns deles, únicos. O em questão tratado (objeto de estudo), ocupa as páginas 134-136 da coleção e o seu código é 168 Gol. (codex 168), está escrito em árabe e seu acesso se dá pelo site Brill Online Primary Sources ${ }^{6}$ a partir do pagamento de uma taxa. Após o pagamento, o cliente tem acesso a todas as obras raras do repositório, em forma de imagens digitalizadas, e tem permissão para navegar, pesquisar e visualizar o conteúdo, não podendo fazer o download.

Para o desenvolvimento do presente estudo, como dito, temos a reescrita do tratado original em árabe, uma versão da tradução em turco e uma outra versão inglesa do tratado. Essas versões se encontram no livro Beyruni'ye Armagan no capítulo intitulado Al Beyruni's Letter on Abu Nasr Mansur's Demonstration of the Sine Law que ocupa as páginas 183 a 197. No livro não há evidências por quem foram feitas e em qual época as traduções foram produzidas, no entanto, o autor indica que o manuscrito traduzido está depositado na universidade de Leiden, sob o códex 168.

Figura 2 - capa do livro em que se encontram as três versões do tratado

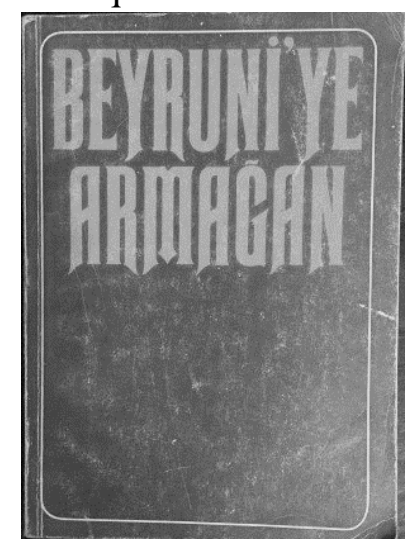

Fonte: Sociedade Histórica da Turquia (1974, capa).

\footnotetext{
${ }^{6} \mathrm{https}: / /$ www.brillonline.com/
} 
Figura 3 - localizando o capítulo no sumário do livro

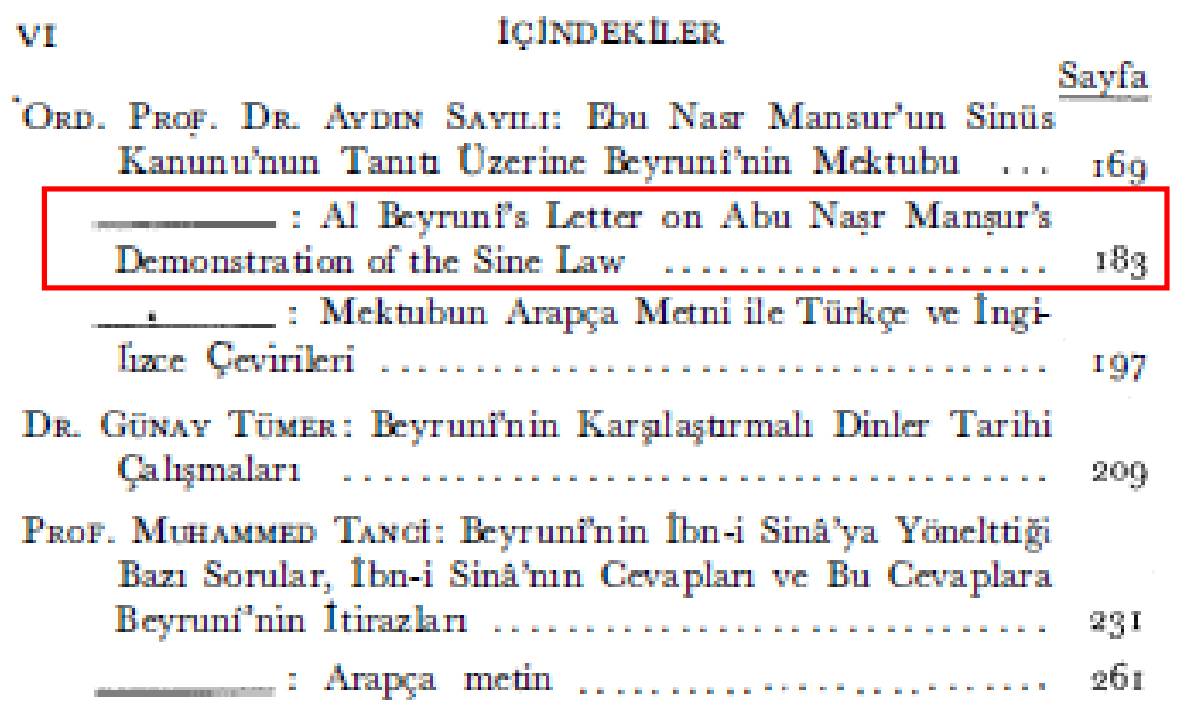

Fonte: Sociedade Histórica da Turquia (1974, p. 6).

No que diz respeito às versões do texto, o autor do capítulo deixa claro que o manuscrito está desgastado em algumas partes, no entanto, o contexto permite que palavras e/ou letras sejam adicionadas. As partes ilegíveis se encontram destacadas entre parágrafos na versão da tradução. Saylin (1974), acrescenta que o manuscrito original é um texto escrito de forma contínua e a tradução por ele realizada é dividida em parágrafos. O referido autor ainda salienta que letras e pontos, que ocasionalmente foram omitidos na versão original, foram considerados por ele na tradução.

$\mathrm{Na}$ tentativa de elucidar sobre as mudanças que foram feitas no documento, Saylin (1974, p. 186, tradução nossa) ${ }^{7}$ esclarece que

\begin{abstract}
O manuscrito está comido por vermes em algumas partes. Felizmente, porém, o contexto permite emendar e completar, sem muita dificuldade, as pequenas lacunas que assim surgiram. As palavras e letras adicionadas para preencher essas lacunas foram colocadas entre colchetes no texto impresso. Em quatro lugares, falta a palavra seno no manuscrito, e não há dúvida de que não foram deixados de fora por engano.
\end{abstract}

\footnotetext{
${ }^{7}$ No original: "The manuscript is badly worm-eaten in parts. Fortunately, however, the context makes it possible to emend and complete, without much difficulty, the small lacunas that heve thus come into being. The words and letters added in order to fill these gaps have been placed in square brackets in the printed text. In four places the word sine is missing in the manuscripit, and there ir no question og their not having been left out by mistake." (SAYLIN, 1974, p. 186)
} 
Figura 4 - modificações feitas pelo autor no conteúdo da carta

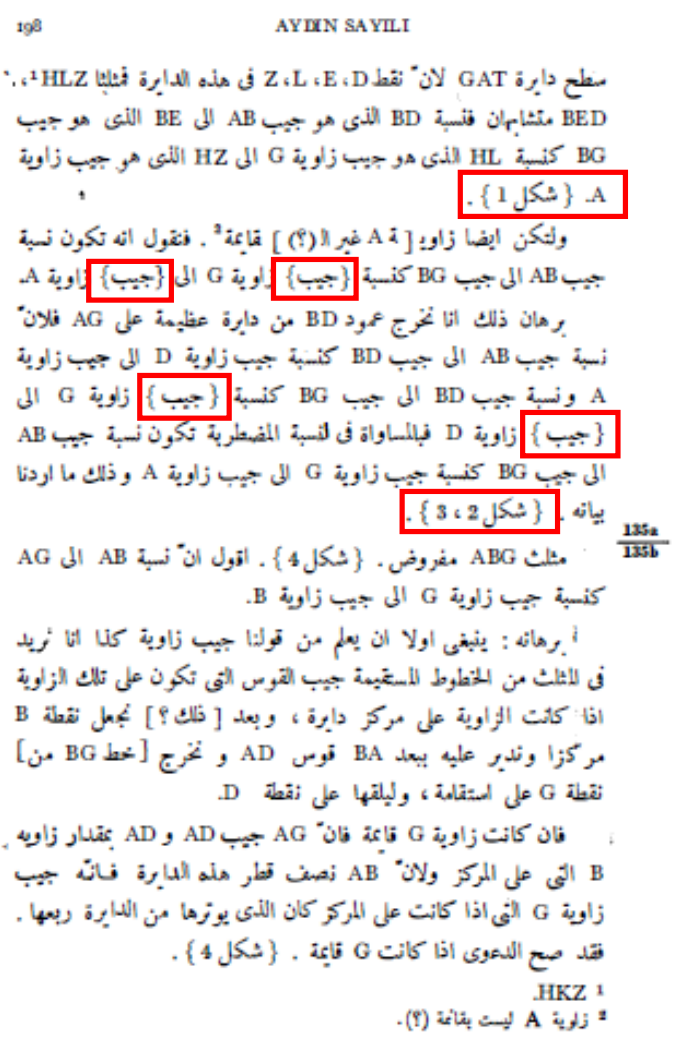

Fonte: Sayili (1974, p. 198).

De ante mão, apesar de existir a limitação dos autores não saberem o idioma árabe, podemos intuir que as partes destacadas dentro dos retângulos vermelhos na figura 03 são os senos que Saylin (1974) menciona ter acrescentado, tendo em vista duas evidências conclusivas: a primeira delas é que as palavras são notadamente as mesmas e não existe em outro parágrafo tal demarcação quatro vezes consecutivas da mesma palavra; uma outra modificação notada é que, a medida que se avança na leitura da tradução, o autor faz referência a um conjunto de figuras da carta (primeira e última marcação em vermelho da figura 03), que juntamente aos enunciados, ajuda no entendimento da proposição.

A partir de um sobrevoo no documento foi identificado que a carta, que está escrita na forma de um manuscrito contínuo, contém uma apresentação, quatro demonstrações que seguem uma estrutura fixa de exposição composta de anunciação, seguida da respectiva demonstração e, por fim, uma saudação final. No mais, vale ressaltar que, conforme já mencionado, dentro dessas demonstrações podemos verificar seis casos 
relativos à Lei dos $\operatorname{Senos}^{8}$, identificando que os três primeiros casos, que correspondem as duas primeiras demonstrações, exemplificam tal lei aplicada à Geometria Esférica, enquanto os três últimos casos, que correspondem as duas últimas demonstrações, trazem a validade do enunciado (da lei dos senos) para a Geometria Plana.

A seguir, apresentamos o Quadro 01 com alguns apontamentos que visam fazer, sumariamente, uma apreciação da estrutura do nosso objeto de estudo, a carta.

Quadro 1 - Quadro-resumo contendo esclarecimentos sobre a estrutura da carta

\begin{tabular}{|c|c|}
\hline $\begin{array}{l}\text { PARTE DA } \\
\text { CARTA }\end{array}$ & APRECIAÇÕES \\
\hline Apresentação & $\begin{array}{l}\text { Corresponde ao primeiro parágrafo da carta, al-Biruni (973-1048) } \\
\text { afirma trazer à tona contribuições de Abu Nasri Mansur ibn Ali ibn } \\
\text { Iraque (960-1036) e explicita, ainda, indícios de relações do autor } \\
\text { com questões de natureza religiosa. }\end{array}$ \\
\hline $1^{\mathrm{a}}$ demonstração & $\begin{array}{l}\text { Nesse caso, al-Biruni traz uma demonstração da lei dos senos para } \\
\text { o caso de um triângulo esférico ABG retângulo em A. Quanto a } \\
\text { demonstração, vale ressaltar que ela é feita por uma construção que } \\
\text { possibilita que uma semelhança de triângulos }{ }^{9} \text { seja usada com o } \\
\text { propósito que a relação pretendida seja apresentada. }\end{array}$ \\
\hline $2^{\mathrm{a}}$ demonstração & $\begin{array}{l}\text { Se divide em dois casos. Traz o caso em que um ângulo A do } \\
\text { triângulo esférico ABG é agudo, ou seja, } 0^{\circ} \leq A<90^{\circ} \text {. E o caso } \\
\text { em que o mesmo ângulo é obtuso, ou seja, } 90^{\circ}<A<180^{\circ} \text {. Em } \\
\text { ambos os casos a demonstração se dá por uma construção que } \\
\text { permite o uso direto da } 1^{\text {a }} \text { demonstração. }\end{array}$ \\
\hline $3^{\mathrm{a}}$ demonstração & $\begin{array}{l}\text { Traz esclarecimentos para expressão "o seno de tal e tal ângulo", } \\
\text { termo que comumente é usado no decorrer da carta. No mais, } \\
\text { apresenta a demonstração da lei dos senos, dessa vez, associada à } \\
\text { geometria plana, abordando o caso do triângulo plano ABG. Essa } \\
\text { demonstração se divide em duas partes, sendo a primeira delas } \\
\text { para o caso de o triângulo ser retângulo em G e a segunda delas, } \\
\text { para quando G é um ângulo agudo. }\end{array}$ \\
\hline $4^{\mathrm{a}}$ demonstração & $\begin{array}{l}\text { A última demonstração compreende uma apresentação que seria } \\
\text { uma espécie de continuação da } 4^{\text {a }} \text { demonstração. Nela al-Biruni } \\
\text { traz o caso em que a lei dos senos é validada para um triângulo } \\
\text { ABG obtuso em G. }\end{array}$ \\
\hline
\end{tabular}

\footnotetext{
${ }^{8}$ A lei dos senos é uma relação matemática de proporção que determina que num triângulo qualquer, a relação do seno de um ângulo é sempre proporcional à medida do lado oposto a esse ângulo. Tal enunciado é válido tanto para Geometria Euclidiana quanto para Geometria Esférica (CARITÁ, 2018).

${ }^{9} \mathrm{Na}$ tradução que esse projeto adota como base, o autor usa o termo semelhança de triângulos quando (the triangles HLZ and BED are similar). Esse termo é usado quando o autor relaciona os lados de dois triângulos por meio da igualdade entre dois quocientes, isso é feito de modo retórico.
} 
\begin{tabular}{|l|l|} 
Saudações finais & $\begin{array}{l}\text { Corresponde ao último parágrafo da carta e deixa claro que é } \\
\text { escrita por al-Biruni e indica Abû Said como destinatário. }\end{array}$ \\
\hline
\end{tabular}

Fonte: elaborado pelos autores (2021)

Como forma de apresentar indícios das informações colocadas anteriormente no Quadro 01, exemplificamos a saudação inicial trazida por al-Biruni, em sua carta, ilustrada na figura 4 da sequência. Essa parte, corresponde ao primeiro parágrafo, onde ele atribui ao príncipe Abu Nasri Mansur ibn Ali ibn Iraque (970 - 1036) a criação da Lei dos senos e, na oportunidade, ele o saúda desejando que Deus (Alá) o abençoe e conceda vida longa, fazendo menção a questões de caráter religioso.

Figura 5 - Apresentação ${ }^{10}$

\section{TRANSLATION OF THE ARABIC TEXT}

Derivations found by the virtuous shaykh Abû Nașr Manșûr ibn 'Alî, the close relative of the Amir of the Believers, may God support and sterngthen him.

Fonte: Sayili (1974, p.205).

As demonstrações apresentadas são realizadas de forma construtiva com recorrência a descrição da representação visual dos resultados que pode ser ilustrada por desenhos, ou seja, à medida que as figuras são construídas vão sendo formulados argumentos que, de forma estratégica, são usados para mostrar a relação pretendida num modelo retórico (sem a notação algébrica atual).

Cabe enfatizar que esse tratamento dado a apresentação dos elementos da carta pode ter sido uma herança da forma de pensar grega. Por exemplo, a forma retórica que a demonstração é apresentada na carta se assemelha a uma estrutura de pensamento que conhecemos hoje por Álgebra Geométrica, essa linguagem não se utilizava de símbolos, mas somente de uma linguagem escrita e é inerente ao pensamento grego. Por outro lado, a lógica rigorosa com que o pensamento é orientado, de modo a mostrar a relação pretendida, também lembra a forma construtiva e indutiva do pensar grego. (MUNIZ, 2020)

10 "Derivações encontradas pelo virtuoso Shaykn Abû Nasr Mansûr Ibn Ali, ao parante do Amir, que Deus o apoie e o alongue”. (SAYLIN, 1974, p.205, tradução nossa). 
Com ênfase na Matemática/conteúdo presente na carta e na tentativa de fazer uma elucidação de como todos os resultados são apresentados no documento, traremos como exemplo a demonstração 01 presente na carta, destacando o enunciado que se refere a lei dos senos (Figura 6) e, complementarmente, para auxiliar na visualização e entendimento, apresentaremos a Figura 7 que está na carta e tem associação direta a demonstração 01. Tais figuras estão ilustradas adiante, respectivamente.

Figura 6 - Enunciado da demonstração 01 da carta de al-Biruni com ênfase na lei dos senos mencionada $^{11}$

TRANSLATION OF THE ARABIC TEXT

Derivations found by the virtuous shaykh Abû Nașr Manșûr ibn 'Alî, the close relative of the Amir of the Believers, may God support and sterngthen him.

Let the triangle $\mathrm{ABG}$ be on the surface of a sphere, its sides being arcs of great circles, and let the angle $\mathrm{A}$ be a right angle. (Figure I). I assert that the ratio of the sine of $\mathrm{AB}$ to the sine of $\mathrm{BG}$ is equal to the ratio of the sine of the angle $\mathrm{G}$ to the sine of the angle A.

Fonte: Sayili (1974, p.205).

Figura 7 - Triângulo Esférico ABG associado a demonstração 01 na carta de al-Biruni para o qual a lei dos senos mencionada é válida

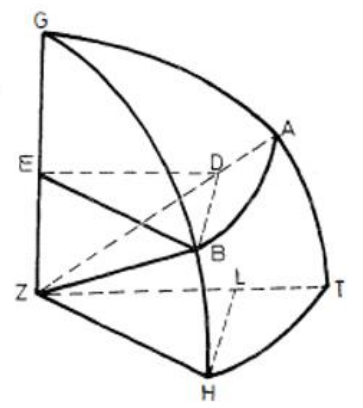

Fonte: Sayili (1974, p. 193).

Nesse sentido, a lei dos senos, exemplificada por meio de um caso, em todas as 4 demonstrações presentes na carta, os comprimentos de arcos da esfera (lados do triângulo esférico $^{12}$ ) com os ângulos esféricos, ou simplesmente lados do triângulo com seus ângulos, no caso do triângulo plano, de modo que a razão entre o seno de um desses arcos

11 "Deixe o triângulo ABG estar na superfície de uma esfera, seu lado são arcos de grandes círculos, deixe o ângulo A ser um ângulo reto (figura 1). Eu afirmo que a razão entre o seno de $\mathrm{AB}$ e o seno de BG é igual à razão entre o seno do ângulo G e o seno do ângulo A”. (SAYLIN, 1974, p.205, tradução nossa).

${ }^{12}$ Região da esfera limitada por três segmentos de circunferências máximas. 
e o seno do ângulo imediatamente oposto a ele seja uma constante para os três casos possíveis. Em notações modernas, a lei dos senos trazida na carta poderia ser expressa pela Equação (1) mostrada a seguir.

$$
\frac{\operatorname{sen}(G B)}{\operatorname{sen}(\hat{A})}=\frac{\operatorname{sen}(A G)}{\operatorname{sen}(\hat{B})}
$$

Conforme já enfatizado, al-Biruni usa o modelo retórico para relatar os passos da construção que assegura seus resultados. Tal estrutura é observada nos demais apontamentos do documento. Contudo, nos limitamos neste artigo a essa apreciação preliminar e com isto, partimos para nossas considerações finais.

\section{Notas finais}

Com a organização e sistematização das informações nesse trabalho disponibilizamos a comunidade acadêmica dados importantes acerca de um documento histórico escrito por al-Biruni que, mesmo depois de 10 séculos de sua existência, ainda carece de exploração e estudo devido. Trazemos informações sobre o documento original, exploramos sua estrutura, trazemos à tona o seu conteúdo e damos vez a uma produção de História da Matemática Islâmica na literatura em História da Matemática no Brasil. A partir disso, chegamos em três aspectos que podem ser de fundamental importância para nortear a construção de uma narrativa mais contextualizada sobre o documento e seu conteúdo.

O primeiro aspecto surge do enlace entre os três personagens presentes na carta. Na saudação final, vemos como remetente uma pessoa chamada Abu Said e no início, alBiruni destaca que apresentará no conteúdo da carta derivações sobre a lei dos senos que foram encontradas por Abû Nasr Mansûr Ibn Ali. Assim, vemos como importante entender qual a relação entre Abu Arrayhan Muhammad ibn Ahmad al-Biruni (973 1048), Abu Said Ahmad ibn Muhammad Al-Sijzi (945 - 1020) e Abu Nasr Mansur ibn Ali ibn Iraque (970 - 1036) entorno da produção desse documento.

O segundo aspecto diz respeito a forma como essas demonstrações foram estruturadas. Todas são demonstrações essencialmente geométricas que são feitas por meio de construção enunciada de modo retórico, ou seja, os desenhos são retoricamente 
construídos e à medida que essa construção vai sendo empreendida, o resultado pretendido se efetiva. A organização, sistematização e a via usada para demonstração (linguagem escrita que narra os passos da construção) são características eminentes do pensamento grego que muito influenciou a civilização islâmica, particularmente, medieval, estudar tal relação pode ser um caminho para localizar o documento dentro de uma malha histórica (SAITO, 2015), de modo que seja possível estabelecer relações do documento com outras produções geométricas, em especial, as que dizem respeito a Trigonometria Triangular Esférica além de outras esferas do conhecimento não só de natureza matemática.

E o terceiro aspecto, mas não menos importante, é a escolha do gênero textual carta para disseminação do conhecimento e informações na época. A carta estabelece relações entorno dos interlocutores e marca uma das principais características da constituição do conhecimento islâmico a partir da leitura do conhecimento em trânsito. Dentre os pontos importantes que são despertados a partir da escolha desse gênero textual, talvez, o mais significativo deles seja entender a dinâmica de produção do conhecimento da civilização islâmica da Idade Média registrando marcas da personalidade de quem a escreve como por exemplo a influência da cultura helenística e dos aspectos teológicos.

Por fim, consideramos que os documentos não são historicamente neutros e podem ser vistos enquanto produto de um processo histórico capaz de suscitar muitas descobertas em campos do conhecimento diversos. Assim, entender as questões colocadas anteriormente e outras que ainda surgirão no processo de busca compreenderá trabalhos futuros que serão desdobramentos diretos desse trabalho inicial de exploração do documento.

\section{Referências}

CARITÁ, Lucas Antonio. Leis dos cossenos e senos esféricos: demonstrações matemáticas para ferramentas astronômicas. Revista Univap, São José dos Campos/SP, v. 24, n. 46, p. 10-18, 2018. Disponível em:

〈https://revista.univap.br/index.php/revistaunivap/article/view/330>. Acesso em: 20 abr. 2021.

FONTELLES, Mauro José et al. Metodologia da pesquisa científica: diretrizes para a elaboração de um protocolo de pesquisa. Revista paraense de medicina, Pará, v. 23, n. 3, p. 1-8, jul./set. 2009. Disponível em: <http://files.bvs.br/upload/S/01015907/2009/v23n3/a1967.pdf>. Acesso em: 20 abr. 2021. 
GAFUROV, Bobojan. AL-BIRUNI, a universal genius who lived in Central Asia a thousand years ago. Paris: Unesco, 1974. Disponível em: < https://unesdoc.unesco.org/ark:/48223/pf0000050318>. Acesso em: 04 jan. 2021.

GIL, Antônio Carlos. Como elaborar projetos de pesquisa. São Paulo: Atlas, 2017.

GODOY, Arilda Schmidt. Introdução à pesquisa qualitativa e suas possibilidades. RAE - Revista de Administração de Empresas, São Paulo, v. 35, n. 2, p. 57-63, mar./abr. 1995.

KAUARK, Fabiana da Silva; MANHÃES, Fernanda Castro; MEDEIROS, Carlos Henrique. Metodologia da pesquisa: um guia prático. Itabuna: Via Litterarum, 2010. Disponível em: < http://www.pgcl.uenf.br/arquivos/livrodemetodologiadapesquisa2010_011120181549.p df >. Acesso em: 05 jan. 2021.

MARTÍNEZ, Leonardo Fabio Pérez. Questões socio científicas na prática docente: Ideologia, autonomia e formação de professores. São Paulo: Editora UNESP, 2012. Disponível em: < http://books.scielo.org/id/bd67t〉. Acesso em: 06 jan. 2021.

MUNIZ, Jéssica Targino. Soluções de equações quadráticas por 'Abd al Hamid Ibn Turk na formação inicial do professor de matemática: uma perspectiva orientada pela história da matemática. 2020. 276f. Dissertação (Mestrado Profissional em Ensino de Ciências Naturais e Matemática) - Centro de Ciências Exatas e da Terra, Universidade Federal do Rio Grande do Norte, Natal, 2020.

O'CONNOR, John J.; ROBERTSON, Edmund F. Abu Arrayhan Muhammad ibn Ahmad al-Biruni. MacTutor History of Mathematics archive, Escócia, nov. 1999. Disponível em: < http://www-history.mcs.standrews.ac.uk/Biographies/Al-Biruni.html >. Acesso em: 27/03/2021.

SAITO, Fumikazu. História da matemática e suas (re)construções contextuais. São Paulo: Editora Livraria da Física, 2015.

SAITO, Fumikazu; DIAS, Marisa da Silva. Interface entre história da matemática e ensino: uma atividade desenvolvida com base num documento do século XVI. Ciência \& Educação, Bauru, v. 19, n. 1, p. 89-111, 2013. Disponível em: < https://www.scielo.br/pdf/ciedu/v19n1/07.pdf >. Acesso em: 04 jan. 2021.

SAYLI, Aydin. Al Beyruni's Letter on Abu Nasr Mansur's Demonstration of the Sine Law. In: Sociedade Histórica da Turquia (org.). BEYRUNI'YE ARMAGAN. Ancara: Türk Tarih Kurumu Basimevi, 1974. p. 183-197.

SÁ-SILVA, Jackson Ronie; DE ALMEIDA, Cristóvão Domingos; GUINDANI, Joel Felipe. Pesquisa documental: pistas teóricas e metodológicas. Revista brasileira de história \& ciências sociais, Rio Grande do Sul, v. 1, n. 1, p. 1-15, jan./jun. 2009. 
Disponível em: $<$ https://periodicos.furg.br/rbhcs/article/view/10351/pdf $>$. Acesso em: 09 jan. 2021.

SOUSA, Giselle Costa de. Aliança entre HM, TDIC e IM: fundamentos e aplicações. In REMATEC: Revista de Matemática, Ensino e Cultura, Ano 15, Fluxo Contínuo, 2020, p.117-136.Disponível em:

$<$ http://www.rematec.net.br/index.php/rematec/article/view/239/202 >. Acesso em: 07 jan. 2021.

Recebido em: 03 / 03 / 2021

Aprovado em: 23 / 04 / 2021 